Genetics and Molecular Biology, 35, 4 (suppl), 939-946 (2012)

Copyright (C) 2012, Sociedade Brasileira de Genética. Printed in Brazil

www.sbg.org.br

Research Article

\title{
The TP53 fertility network
}

Diego d'Avila Paskulin ${ }^{1,2}$, Vanessa Rodrigues Paixão-Côrtes ${ }^{1,3}$, Pierre Hainaut ${ }^{4}$, Maria Cátira Bortolini ${ }^{1,3}$ and Patricia Ashton-Prolla ${ }^{1,2,5^{*}}$

${ }^{1}$ Programa de Pós-Graduação em Genética e Biologia Molecular, Universidade Federal do Rio Grande do Sul, Porto Alegre, RS, Brazil.

${ }^{2}$ Laboratório de Medicina Genômica, Hospital de Clínicas de Porto Alegre, Porto Alegre, RS, Brazil.

${ }^{3}$ Laboratório de Evolução Humana e Molecular, Universidade Federal do Rio Grande do Sul, Porto Alegre, RS, Brazil.

${ }^{4}$ International Prevention Research Institute, Lyon, France.

${ }^{5}$ Serviço de Genética Médica, Hospital de Clínicas de Porto Alegre, Porto Alegre, RS, Brazil.

\begin{abstract}
The TP53 gene, first described in 1979, was identified as a tumor suppressor gene in 1989, when it became clear that its product, the p53 nuclear phosphoprotein, was frequently inactivated in many different forms of cancers. Nicknamed "guardian of the genome", TP53 occupies a central node in stress response networks. The p53 protein has a key role as transcription factor in limiting oncogenesis through several growth suppressive functions, such as initiating apoptosis, senescence, or cell cycle arrest. The p53 protein is directly inactivated in about $50 \%$ of all tumors as a result of somatic gene mutations or deletions, and over $80 \%$ of tumors demonstrate dysfunctional p53 signaling. Beyond the undeniable importance of p53 as a tumor suppressor, an increasing number of new functions for p53 have been reported, including its ability to regulate energy metabolism, to control autophagy, and to participate in various aspects of differentiation and development. Recently, studies on genetic variations in TP53 among different populations have led to the notion that the p53 protein might play an important role in regulating fertility. This review summarizes current knowledge on the basic functions of different genes of the TP53 family and TP53 pathway with respect to fertility. We also provide original analyses based on genomic and genotype databases, providing further insights into the possible roles of the TP53 pathway in human reproduction.
\end{abstract}

Keywords: TP53, fertility, p53 network.

\section{The TP53 Gene, its Products and Regulation}

The transcription factor $\mathrm{p} 53$ is encoded by the Tumor Protein $\mathrm{p} 53$ gene (TP53, OMIM 191170), which in humans is located on the short arm of chromosome 17 (17p13.1). TP53 is composed of 19,198 nucleotides, spanning 11 exons and encoding a 393 amino acid protein that functions primarily as a transcription factor and is biologically active as a homotetramer. The $\mathrm{p} 53$ protein has six major domains and its expression is subject to multiple regulation, at transcriptional, post-transcriptional, translational and posttranslational levels (Hollstein and Hainaut, 2010). A further level in complexity is generated by the expression of p53 as up to 10 distinct isoforms produced by alternative splicing, alternative promoter usage, and alternative translation initiation (Bourdon et al., 2005).

Send correspondence to Patricia Ashton-Prolla. Serviço de Genética Médica, Hospital de Clínicas de Porto Alegre, Rua Ramiro Barcelos 2350, 90035-903 Porto Alegre, RS, Brazil. E-mail: pprolla@ hcpa.ufrgs.br.
The $\mathrm{p} 53$ protein functions as a multitarget transcription factor. Upon cellular stress signals (including DNA damage, oncogene activation, hypoxia, nutrient deprivation, telomere erosion and ribosomal stress) p53 is activated through protein stabilization and post-translational modifications, allowing full p53 transactivation potential (Kruse and $\mathrm{Gu}, 2009$ ). Induction of growth arrest or cell death upon activation of $\mathrm{p} 53$ prevents the replication of damaged DNA and the division of genetically altered cells, therefore, playing an important role in maintaining the integrity of the genome (Lane, 1992). The importance of p53 as a tumor suppressor is illustrated by the observation that many individuals affected by Li-Fraumeni syndrome (a high penetrance hereditary cancer syndrome that predisposes to multiple early-onset cancers) are carriers of loss of function germline mutations in TP53 (Malkin et al., 1990).

The $\mathrm{p} 53$ protein interacts with a large number of partner proteins, but special attention has been given to the p53-Mdm2 interaction. Among other biochemical func- 
tions, the Mdm2 protein (encoded by MDM2, the human homolog of the Murine Double Minute 2 gene, OMIM 164785) operates as E3 ubiquitin ligase to induce $\mathrm{p} 53$ polyubiquitination, mediating its nuclear export and targeting it to the proteasome for degradation (Lain and Lane, 2003). Interestingly, Mdm2 forms a negative-feedback loop with $\mathrm{p} 53$, as $M D M 2$ transcription is positively and directly regulated by p53 (Michael and Oren, 2003). This autoregulatory loop maintains a delicate equilibrium in the precise regulation of protein levels and activities of both p53 and Mdm2. Like MDM2, its structural homolog, MDM4 (OMIM 602704), can also bind directly to p53, inhibiting its ability to function as a transcriptional activator, as well as regulating its stability, most likely through interactions with Mdm2 (Toledo et al., 2006). However, unlike Mdm2, Mdm4 (also known as MdmX), is devoid of autonomous E3 ligase activity. Another important regulator of p53 function is the Ubiquitin-Specific Protease 7, USP7 (OMIM 602519), which de-ubiquitylates p53 and protects it from proteasome-mediated degradation (Shan et al., 2008). The pivotal role of Mdm2 and Mdm4 in the control of p53 function supports the notion that polymorphisms at these loci might be potential modifiers of p53 function (Atwal et al., 2009).

\section{The TP53 Family}

The TP53 family of genes includes TP53 and two structural and functional p53 homologs: TP63 (OMIM 603273) and TP73 (OMIM 601990). These three members share a very high homology in the DNA binding domain, as well as in overall protein architecture, with $\mathrm{p} 63$ and $\mathrm{p} 73$ being more closely related to each other than to $\mathrm{p} 53$ (Belyi et al., 2010). Although TP63 and TP73 have been discovered well after $\mathrm{p} 53$, they seem to have appeared earlier than TP53 during evolution. The current view is that the three genes derive from a single ancestor which was most likely a p63/p73-like gene (Nedelcu and Tan, 2007). The overall protein architecture is highly conserved from Drosophila to man, and consists of a central sequence specific DNA binding domain (DBD), an N-terminal transactivation domain (TA) and a C-terminal oligomerization domain (OD). p63 and p73 contain a sterile $\alpha$-motif (SAM) domain at their $\mathrm{C}$-terminus that plays a role in protein-protein interactions and which has no structural equivalent in p53, and a transcription inhibition domain (TID) that decreases their transcriptional activity by enforcing a closed conformation through interaction with the amino-terminal TA domain (Straub et al., 2010). The competition for binding to DNA through their structurally similar DBDs suggests that $\mathrm{p} 53$, p63 or p73 may cooperate or compete for the regulation of common transcriptional targets.

Given that the main forms of $\mathrm{p} 63$ and $\mathrm{p} 73$ are the so-called delta- $\mathrm{N}$ isoforms lacking the main, $\mathrm{N}$-terminal TA domain, interferences between the three proteins can result in either synergistic effects or dominant-negative effects, in which p 63 or p 73 isoforms may down-regulate p53 (Levine et al., 2011). While p53 acts mainly in response to different stresses, p63 is one of the major transcription factors required for the development of stratified epithelia, making it essential for the limb and for the formation of a functional skin (Gonfloni et al., 2009; Mills et al., 1999). Accordingly, $\triangle \mathrm{Np} 63$ isoforms play distinct roles in regulating epithelium-mesenchyme interactions through the regulation of TGF $\beta$, resulting in a more invasive phenotype in the presence of $\Delta \mathrm{Np} 63 \gamma$ (Lindsay et al., 2011; Oh et al., 2011). p73 is involved in the development of the immune and central nervous system (Belyi et al., 2010) and has important functions in the regulation of the spindle assembly checkpoint (SAC) during meiosis and mitosis (Tomasini et al., 2008), as it prevents aneuploidy through sensing the improper attachment of sister chromatids to the mitotic or meiotic spindle and delays anaphase until chromosomes are correctly oriented for segregation (Gardner and Burke, 2000). Considering these observations, a functional divergence among p53, p63 and p73 clearly emerges. While p53 behaves as a canonical tumor suppressor gene which is mostly active after induction by various forms of stress, both p63 and p73 play major roles in normal ectodermal differentiation and neurogenesis and only a secondary one in response to the types of stress that activate p53.

\section{TP53 Regulates Reproduction Through LIF}

The current knowledge on $\mathrm{p} 53$ regulation and functions has been the subject of a detailed recent review (Vousden and Prives, 2009). However, most studies have concentrated on p53 as a stress-induced tumor suppressor gene, and little is known about its function in normal cellular processes. The $\mathrm{p} 53$ protein accomplishes its function by transcriptionally regulating target genes. In 2002, several genomic DNA sequences were detected where the $\mathrm{p} 53$ protein was most likely able to bind and activate transcription (Hoh et al., 2002).

Among these, a potential candidate was the gene encoding the leukemia inhibitory factor (LIF, OMIM 159540), a secreted cytokine that is critical for blastocyst implantation (Stewart et al., 1992). This gene contains a putative p53-binding consensus DNA sequence in intron 1, which is conserved in both mouse and human gene sequences (Hu et al., 2007a). In fact, implantation cannot occur unless epithelial cells lining the uterus are exposed to LIF (Stewart et al., 1992), most likely expressed at the onset of implantation, which occurs at day 4 of pregnancy in mice (day 12 in humans). LIF null mice have a defect in maternal reproduction caused by the complete lack of uterine decidualization at the implantation stage, with consequent failure of blastocyst implantation, which can be rescued by LIF injection at the implantation stage (the 4th day of pregnancy in mice) (Chen et al., 2000). Hu et al. 
(2007b) demonstrated that $\mathrm{p} 53$ plays a significant role in fertility, since p53-null female mice present reduced uterine expression of LIF and, as expected, reduced maternal reproduction due to impaired implantation functions. Administering LIF to p53 deficient female mice at day 4 of pregnancy significantly increased the pregnancy rate and litter size with improved blastocyst implantation. These findings demonstrate that inactivation of $\mathrm{p} 53$ decreases the levels and function of uterine LIF, thus indicating a function for $\mathrm{p} 53$ in maternal reproduction through the regulation of LIF.

In addition, estrogen is also involved in the regulation of transient LIF expression at the implantation stage (Chen et al., 2000), mediated through its nuclear receptor alpha (ER $\alpha$, encoded by ESR1, OMIM 133430). Feng et al. (2011) demonstrated a significant increase in nuclear ER $\alpha$ levels in endometrial glands at the implantation stage in mice, and concluded that the increased expression of LIF at this stage requires the activation of $\mathrm{p} 53$, increased estrogen levels, and activated ER $\alpha$.

\section{Single Nucleotide Polymorphisms and Infertility}

Considering the strict regulation of LIF by $\mathrm{p} 53$, it is reasonable to expect that modulation of p53 function by single nucleotide polymorphisms (SNPs) in TP53 and TP53-related genes may affect fertility. In humans there are many naturally occurring SNPs in genes at critical nodes in the TP53 pathway, including TP53, MDM2, MDM4, and USP7, all of which have known functional variants that can modify the levels or activity of the $\mathrm{p} 53$ protein (Atwal et al., 2009; Bond et al., 2004). One of the most commonly studied TP53 variants, the non-silent polymorphism Pro72Arg ( $\mathrm{rs} 1042522 ; \mathrm{C} / \mathrm{G}$ ), is associated with biochemical and functional differences in protein functions, since the protein carrying the Pro72 allele is more efficient in initiating senescence and cell cycle arrest, while the one with the Arg72 allele is more active in inducing apoptosis and suppressing cellular transformation (Dumont et al., 2003; Thomas et al., 1999). The Pro72 isoform is also observed in other primates, including the chimpanzee, while the Arg72 one is only present in humans, thus suggesting that the $\mathrm{C}$ (Pro72) allele may correspond to the ancestral allele.

Compared with TP53 Pro72, the Arg72 allele presents higher transcriptional activity toward a subset of p53 target genes, including LIF. The induction of LIF is over 2 -fold higher in cells with the Arg72 allele than in cells with the Pro72 allele (Kang et al., 2009), leading to decreased implantation success. Kay et al. (2006) associated the Pro72 allele with recurrent implantation failure and demonstrated that the Pro72 allele is enriched in women with unexplained infertility from an in vitro fertilization clinic, compared with a fertile control population (Kang et al., 2009). In Brazil, Ribeiro Junior et al. (2009) associated the Pro72 allele with intense pain in a cohort of endometriotic patients and Bianco et al. (2011) considered that the Pro72Arg polymorphism was not a risk factor for infertility or endometriosis in Brazilian infertile patients. Interestingly, we found that both TP53 Pro72Arg and MDM4 rs1563828 are associated with twinning in Cândido Godói (Tagliani-Ribeiro et al., 2012), a small town in Brazil remarkable for showing a high frequency of both dizygotic and monozygotic twins (Tagliani-Ribeiro et al., 2011).

An additional remarkable fact regarding Pro72Arg is that the allele frequencies for this SNP vary widely across human populations. For instance, Arg72 frequencies range from $\sim 20 \%$ in some Sub-Saharan populations to $\sim 80 \%$ in northern Europeans, while in Asians the values are intermediate (HapMap and Alfred database, respectively). These distinct allele frequencies promote a level of differentiation $\left(\mathrm{F}_{\mathrm{ST}}\right)$ of $19 \%$ between Caucasians and Yoruba from Nigeria (Table S1). Recently, the complete nuclear genomes of two extinct hominids belonging the genus Homo, Homo neanderthalensis and Denisova specimen were published (Green et al., 2010; Reich et al., 2010). Based on these genomic data sets, compiled from UCSC Genome Browser, only Pro72 is present in both archaic human sequences. Inference from this observation is that the $\mathrm{C} \rightarrow \mathrm{G}$ mutation may have a relatively recent origin, i.e. the $\mathrm{Arg} 72$ variant may be Homo sapiens-specific. Additional studies on archaic human species will be needed to confirm this hypothesis.

The MDM2 SNP309 (rs2279744; T/G) is another commonly described variant that attenuates the TP53 pathway. It is a gain of function variant that increases the affinity of a sequence in $M D M 2$ for the Sp1 transcription factor leading to increased transcription of the $\mathrm{Mdm} 2$ protein, and consequent inhibition or attenuation of the TP53 pathway-mediated tumor suppression functions (Bond et al., 2004). Interestingly, SNP309 is located in a transcriptional enhancer region of $M D M 2$ regulated by estrogen signaling (Phelps et al., 2003). Because SNP309 increases the binding affinity for Sp1, a co-activator of multiple hormone receptors, it could potentially affect the hormone-dependent regulation of $M D M 2$ transcription and result in further elevation of the Mdm2 protein levels, as estrogen preferentially stimulates transcription of the $309 \mathrm{G}$ allele (Hu et al., 2007b). In addition to TP53 Pro72 and MDM2 309G, other variants in TP53-related genes (MDM4, rs1563828: T/C; USP7, rs1529916: T/C; and LIF, rs929271: G/T) have been proposed as functional variants with a role in reproduction, showing differential allele frequencies in young infertile women submitted to in vitro fertilization when compared to fertile women (Kang et al., 2009).

From an evolutionary perspective, TP53 Arg72 and MDM2 309G seem to have been positively selected in European and Asian populations, which can be interpreted as a result of adaptive pressures during the dispersion of Homo sapiens from Africa to other continents (Atwal et al., 2007; Shi et al., 2009; Belyi et al., 2010). Several studies indicate 
that p53 has evolutionarily conserved functions other than acting as a tumor suppressor, and the existence of p53-like proteins in short-lived organisms that do not exhibit adult cancer incidence, such as flies and worms, adds to the argument that tumor suppression was not the original function for p53 and its pathway (Lu et al., 2009). In addition, the major impact of p53 in cancer prevention or longevity in humans likely occurs in post-reproductive years, which would exclude a major evolutionary role associated to these functions. Like TP53 and MDM2, MDM4 and USP7 also appear to have alleles or haplotypes that are under selection pressure and show geographic variations in allele distribution (Atwal et al., 2007; Shi et al., 2009). In a recent study, Feng et al. (2007) reported that SNPs in the TP63 (rs17506395; T/G) and TP73 (rs4648551 G/A and rs6695978 G/A) genes are associated with infertility in women, independently of age for TP63 and specifically in women aged over 35 years for TP73. The authors proposed that the possible mechanisms of infertility associated with variations in TP53 might be impaired implantation, whereas variations in TP63 and TP73 may affect the quality of oocytes and induce chromosomal aneuploidy (Feng et al., 2007).

Based on these findings, it is reasonable to assume that alleles in genes of the TP53 family and TP53 pathway with reproductive implications may have been important targets for selection pressure during the human evolutionary history.

\section{The TP53 Fertility Network}

The p53 protein and its signal transduction pathway are composed of a set of genes and their protein products that are designed to respond to a wide variety of intrinsic and extrinsic stress signals. Although the important interaction between $\mathrm{p} 53$ and $L I F$ is crucial for embryo implantation, current evidence suggests that not only $L I F$, but other genes may be important in the reproductive stages of decidualization and implantation. To further test this hypothesis, we constructed a network with 18 TP53 related genes involved in decidualization and implantation processes, including LIF, MDM2 and others (Figure 1). Genes related to decidualization and implantation were compiled from the Gene Ontology website database using the AmiGO browser. Association among these genes was tested using the STRING 9 software which tests available known and predicted gene/protein interactions (Szklarczyk et al., 2011). This "two-step" approach was chosen to minimize the possibility of false associations during the STRING analysis due to co-existence of words. Table S2 summarizes the 18 genes of this network, as well as their interconnections and wide range of functions. It is important to note that neither p63 nor p73 are on this list, since their main reproduction-related functions refer to the control of ovulation and female germ cell integrity in humans, and they apparently are not involved in decidualization or embryo implantation stages.

This "TP53 Fertility Network" illustrates the importance of multiple genes in these specific stages of human fertility and opens a wide range of possibilities for genetic variation studies in genes not yet being investigated with regard to fertility. For example, IGFBP7 (insulin-like growth factor binding protein 7) is predominantly expressed in the vasculature of developing embryos and regulates vascular endothelial growth factor-A-dependent neoangiogenesis (Hooper et al., 2009). ESR1 (estrogen receptor 1) gene is critical for LIF expression (Feng et al., 2011) and ILIB (interleukin 1, beta) is involved in a variety of cellular activities that are essential for decidualization, including cell proliferation, differentiation, and apoptosis (Ben-Sasson et al., 2009).

An additional analysis to verify if these 18 genes belong to a specific functional cluster was performed using GeneDecks V3 software. Thirteen of them were functionally clustered as having an involvement in the reproductive system (CYP27B1, ESR1, LIF, MEN1, PLA2G4A, PLAU, PPARD, PTGS2, SOD1, SPP1, TP53, UBE2A and VDR). More specifically, seven genes (CALCA, ILIB, LIF, $P P A R D, P T G S 2$, SOD1 and SPP1) were associated with embryo implantation $\left(\mathrm{p}=1 \times 10^{-16}\right)$ and seven $(C Y P 27 B 1$, LIF, PLA2G4A, PPARD, PTGS2, SPP1 and VDR) with decidualization $\left(\mathrm{p}=1 \times 10^{-16}\right)$. It is noteworthy that some genes are present in all functional clusters cited above (e.g. PPARD; peroxisome proliferator-activated receptor delta). This analysis brought additional evidence of the role of these genes in key stages of fertility.

\section{Evolutionary Pattern of the TP53 Fertility Network}

In order to explore certain evolutionary aspects of the network we expanded the analysis on its suitability as a model using two different approaches and taking into consideration inter- (vertebrate) and intra- (human) species variations of the 18 genes that comprise the network.

The first approach was to assess the level of conservation of the genes included in the network along evolutionary lineages using comparative analysis between humans and other 21 vertebrate species. Data were compiled in the STRING 9.0 database whereas the level of identity of the amino acid sequences between humans and the others species was obtained using the LALIGN software. The 18 genes presented variable levels of amino acid sequence conservation (Table S3). Protein preservation among the species belonging to the primate order (human, chimpanzee, orangutan, and rhesus monkey) was on average $97 \%$, while among placental mammals (human, chimpanzee, orangutan, and rhesus monkey, mouse, rat, guinea pig, rabbit, cow, cat, dog, horse, pig, and armadillo) it was $85 \%$. In contrast, the degree of protein identity decreased signifi- 


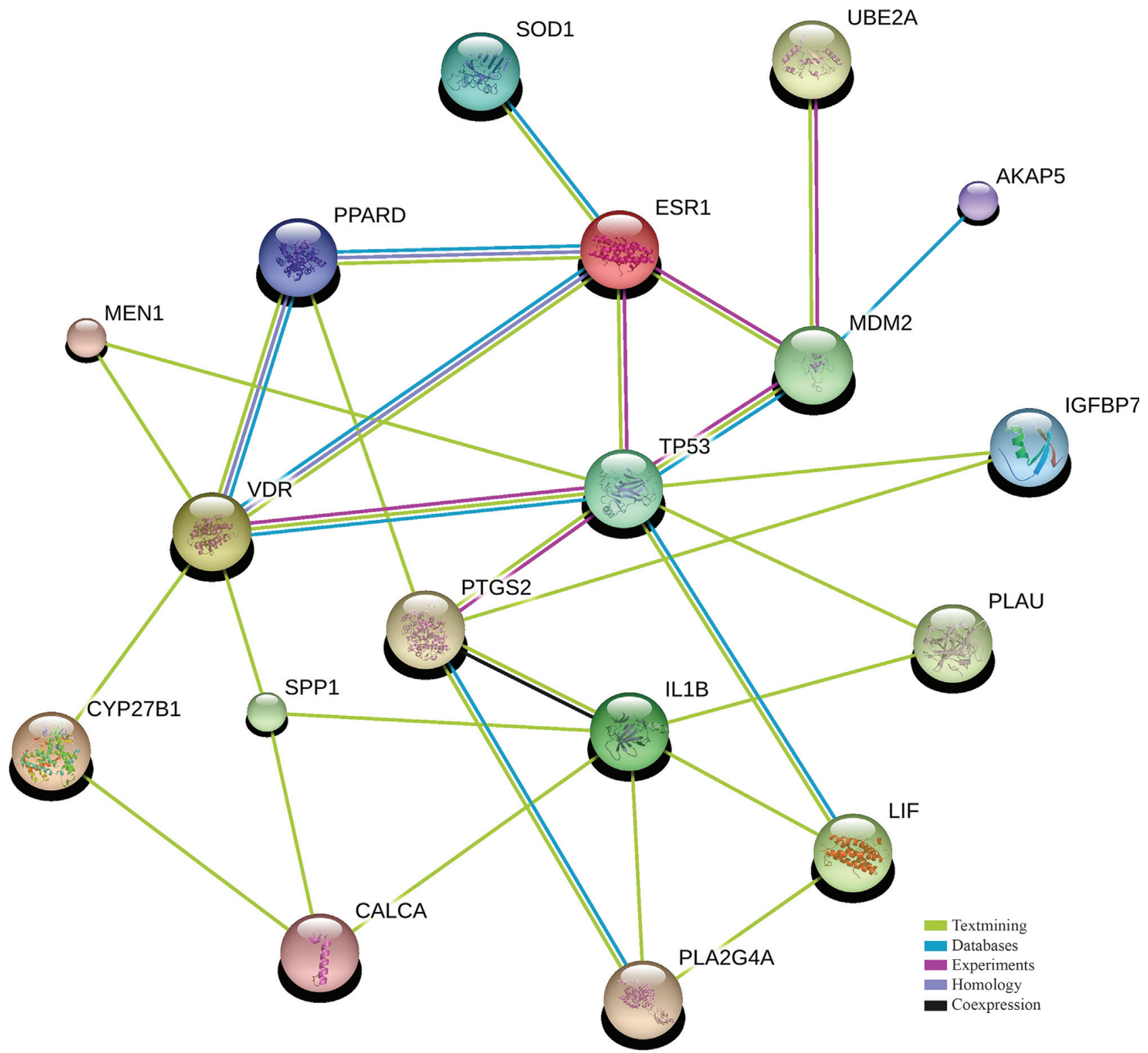

Figure 1 - Eighteen genes of the TP53 Fertility Network. Image created by STRING Software 9.0 with high confidence score (0.7). Different types of lines represent the kind of evidence for the association. AKAP5: A-Kinase anchor protein 5; CALCA: Calcitonin-related polypeptide alpha; CYP27B1: Cytochrome P450; IGFBP7: Insulin-like growth factor binding protein 7; IL1B: Interleukin 1 Beta; ESR1: Estrogen Receptor alpha; $L I F$ : Leukemia inhibitory factor; MDM2; Mouse Double Minute 2 Homolog; MEN1: Multiple Endocrine Neoplasia I; PLA2G4A: Phospholipase A2, group IVA; PLAU: Plasminogen activator urokinase; PPARD: Peroxisome proliferator-activated receptor delta; PTGS2: Prostaglandin-endoperoxide synthase 2; SOD1: Superoxide Dismutase 1, SPP1: Secreted Phosphoprotin 1; TP53: Tumor Protein p53; UBE2A: Ubiquitin-Conjugating Enzyme E2A; VDR: Vitamin D receptor.

cantly (average of $41 \%$ ) when the comparison involved only humans and fish species. The results generated from STRING 9.0 show that overall $90 \%$ of the network's connections (edges) were retrieved in primates, while for placental mammals the value was reduced to $80 \%$. However, when all vertebrates were considered, only $42 \%$ of the network is recovered. These results suggest that some of the 18 network genes may have acquired novel functions in different taxa, throughout vertebrate evolution, in addition to an- cestral functions, a similar situation to that reported previously for the HOX family genes (Chen et al., 2010).

The second approach was to study variation within the 18 genes between human populations. The data were compiled from HapMap and ENSEMBL databases. Using this strategy we identified 10,918 polymorphisms, only $1.4 \%$ of which being non-synonymous changes (Table S4). Of these, 82 (e.g. Pro72Arg) are predicted to be deleterious (Table S5). For most other potentially deleterious polymorphisms no striking difference was found in allele fre- 
quencies among continental populations. However, some notable exceptions can be highlighted. Reminiscent of the Pro72Arg polymorphism, the rs5241 SNP located in the CALCA gene shows a frequency of $17 \%$ in Africans, whereas it is absent in European-descendents. On the other hand, for another SNP (rs2227564) located in the PLAU gene, the rare allele is only present in Euro-Asian populations (23\%-33\%), whereas it is absent in Africans (Table S1). Overall, these examples suggest that selection pressure for specific alleles in defined populations has affected only a small subset of the genes involved in the proposed network.

Since reproduction is central to the evolutionary process, in all vertebrates, as well as in other organisms, the genome is expected to be optimized for reproductive success. However, even among vertebrates there is an immense diversity in how reproduction occurs, including care and rearing of the offspring (de Magalhaes and Church, 2005; Plunkett et al., 2011). There are many reasons in the evolutionary history of each species, including of our own and of other phylogenetically close species, such as Neanderthal, Denisova and chimpanzee that can explain shared and unique reproductive traits. Our results show for instance, that the human fertility network is not identical in all vertebrate species investigated here. An additional complicating factor is that for humans reproductive strategies can have changed drastically due to cultural practices, as well as in response to environmental pressures (e.g. climate change). Thus, it is expected that part of this diversity is the result of variable selection pressures encountered by human populations as they progressively expanded over the world.

Finally, this analysis adds further support to the idea that there is not a unique major effect gene involved in fertility and that an approach based on a wider gene network and taken under an evolutionary perspective may lead to the delineation of a more comprehensive view of the impact of p53 on the complex biology of fertility. Additional investigations at population level, as well as functional studies are needed to clarify the exact implications of the inter(vertebrate) and intra- (human) differences highlighted in the present study.

\section{Acknowledgments}

This study was supported by grants from Conselho Nacional de Desenvolvimento Científico e Tecnológico (CNPq grant 475471/2009-1) and Fundo de Incentivo à Pesquisa do Hospital de Clínicas de Porto Alegre FIPE/HCPA (grant 09-430). DDP and VRPC are supported by grants from $\mathrm{CNPq}$.

\section{References}

Atwal GS, Bond GL, Metsuyanim S, Papa M, Friedman E, Distelman-Menachem T, Ben Asher E, Lancet D, Ross DA, Sninsky J, et al. (2007). Haplotype structure and selection of the MDM2 oncogene in humans. Proc Natl Acad Sci USA 104:4524-4529.

Atwal GS, Kirchhoff T, Bond EE, Montagna M, Menin C, Bertorelle R, Scaini MC, Bartel F, Bohnke A, Pempe C, et al. (2009) Altered tumor formation and evolutionary selection of genetic variants in the human MDM4 oncogene. Proc Natl Acad Sci USA 106:10236-10241.

Belyi VA, Ak P, Markert E, Wang H, Hu W, Puzio-Kuter A and Levine AJ (2010) The origins and evolution of the $\mathrm{p} 53$ family of genes. Cold Spring Harb Perspect Biol 2:a001198.

Ben-Sasson SZ, Hu-Li J, Quiel J, Cauchetaux S, Ratner M, Shapira I, Dinarello CA and Paul WE (2009) IL-1 acts directly on CD4 T cells to enhance their antigen-driven expansion and differentiation. Proc Natl Acad Sci USA 106:71197124.

Bianco B, Christofolini DM, Brandes A, Lerner TG, GonçalvesFilho RP, Souza AM and Barbosa CP (2011) Analysis of codon 72 polymorphism of the TP53 gene in infertile women with and without endometriosis. Rev Bras Ginecol Obstet 33:37-42 (in portuguese).

Bond GL, Hu W, Bond EE, Robins H, Lutzker SG, Arva NC, Bargonetti J, Bartel F, Taubert H, Wuerl P, et al. (2004) A single nucleotide polymorphism in the MDM2 promoter attenuates the p53 tumor suppressor pathway and accelerates tumor formation in humans. Cell 119:591-602.

Bourdon JC, Fernandes K, Murray-Zmijewski F, Liu G, Diot A, Xirodimas DP, Saville MK and Lane DP (2005) p53 isoforms can regulate p53 transcriptional activity. Genes Dev 19:2122-2137.

Chen JR, Cheng JG, Shatzer T, Sewell L, Hernandez L and Stewart CL (2000) Leukemia inhibitory factor can substitute for nidatory estrogen and is essential to inducing a receptive uterus for implantation but is not essential for subsequent embryogenesis. Endocrinology 141:4365-4372.

Chen L, Zhao P, Wells L, Amemiya CT, Condie BG and Manley NR (2010) Mouse and zebrafish Hoxa3 orthologues have nonequivalent in vivo protein function. Proc Natl Acad Sci USA 107:10555-10560.

de Magalhaes JP and Church GM (2005) Genomes optimize reproduction: Aging as a consequence of the developmental program. Physiology (Bethesda) 20:252-259.

Dumon P, Leu JI, Della Pietra $3^{\text {rd }}$ AC, George DL and Murphy M (2003) The codon 72 polymorphic variants of p53 have markedly different apoptotic potential. Nat Genet 33:357365.

Feng Z, Hu W, de Stanchina E, Teresky AK, Jin S, Lowe S and Levine A J (2007) The regulation of AMPK beta1, TSC2, and PTEN expression by p53: Stress, cell and tissue specificity, and the role of these gene products in modulating the IGF-1-AKT-mTOR pathways. Cancer Res 67:3043-3053.

Feng Z, Zhang C, Kang HJ, Sun Y, Wang H, Naqvi A, Frank AK, Rosenwaks Z, Murphy ME, Levine AJ, et al. (2011) Regulation of female reproduction by $\mathrm{p} 53$ and its family members. FASEB J 25:2245-2255.

Gardner RD and Burke DJ (2000) The spindle checkpoint: Two transitions, two pathways. Trends Cell Biol 10:154-158.

Gonfloni S, Di Tella L, Caldarola S, Cannata SM, Klinger FG, Di Bartolomeo C, Mattei M, Candi E, De Felici M, Melino G, et al. (2009) Inhibition of the c-Abl-TAp63 pathway protects mouse oocytes from chemotherapy-induced death. Nat Med 15:1179-1185. 
Green RE, Krause J, Briggs AW, Maricic T, Stenzel U, Kircher M, Patterson N, Li H, Zhai W, Fritz MH, et al.(2010) A draft sequence of the Neandertal genome. Science 328:710-722.

Hoh J, Jin S, Parrado T, Edington J, Levine AJ and Ott J (2002) The p53MH algorithm and its application in detecting p53responsive genes. Proc Natl Acad Sci USA 99:8467-8472.

Hollstein M and Hainaut P (2010) Massively regulated genes: The example of TP53. J Pathol 220:164-173.

Hooper AT, Shmelkov SV, Gupta S, Milde T, Bambino K, Gillen $\mathrm{K}$, Goetz M, Chavala S, Baljevic M, Murphy AJ, et al. (2009) Angiomodulin is a specific marker of vasculature and regulates vascular endothelial growth factor-Adependent neoangiogenesis. Circ Res 105:201-208.

$\mathrm{Hu}$ W, Feng Z, Ma L, Wagner J, Rice JJ, Stolovitzky G and Levine AJ (2007a) A single nucleotide polymorphism in the MDM2 gene disrupts the oscillation of p53 and MDM2 levels in cells. Cancer Res 67:2757-2765.

Hu W, Feng Z, Teresky AK and Levine AJ (2007b) p53 regulates maternal reproduction through LIF. Nature 450:721-724.

Kang HJ, Feng Z, Sun Y, Atwal G, Murphy ME, Rebbeck TR, Rosenwaks Z, Levine AJ and Hu W (2009) Single-nucleotide polymorphisms in the $\mathrm{p} 53$ pathway regulate fertility in humans. Proc Natl Acad Sci USA 106:9761-9766.

Kay C, Jeyendran RS and Coulam CB (2006) p53 tumour suppressor gene polymorphism is associated with recurrent implantation failure. Reprod Biomed Online 13:492-496.

Kruse JP and Gu W (2009) Modes of p53 regulation. Cell 137:609-622.

Lain S and Lane D (2003) Improving cancer therapy by non-genotoxic activation of p53. Eur J Cancer 39:1053-1060.

Lane DP (1992) Cancer. p53, guardian of the genome. Nature 358:15-16.

Levine AJ, Tomasini R, McKeon FD, Mak TW and Melino G (2011) The p53 family: Guardians of maternal reproduction. Nat Rev Mol Cell Biol 12:259-265.

Lindsay J, McDade SS, Pickard A, McCloskey KD and McCance DJ (2011) Role of DeltaNp63gamma in epithelial to mesenchymal transition. J Biol Chem 286:3915-3924.

Lu WJ, Amatruda JF and Abrams JM (2009) p53 ancestry: Gazing through an evolutionary lens. Nat Rev Cancer 9:758-762.

Malkin D, Li FP, Strong LC, Fraumeni Jr JF, Nelson CE, Kim DH, Kassel J, Gryka MA, Bischoff FZ, Tainsky MA, et al. (1990) Germ line p53 mutations in a familial syndrome of breast cancer, sarcomas, and other neoplasms. Science 250:1233-1238.

Michael D and Oren M (2003) The p53-Mdm2 module and the ubiquitin system. Semin Cancer Biol 13:49-58.

Mills AA, Zheng B, Wang XJ, Vogel H, Roop DR and Bradley A (1999) p63 is a p53 homologue required for limb and epidermal morphogenesis. Nature 398:708-713.

Nedelcu AM and Tan C (2007) Early diversification and complex evolutionary history of the p53 tumor suppressor gene family. Dev Genes Evol 217:801-806.

Oh JE, Kim RH, Shin KH, Park NH and Kang MK (2011) DeltaNp63alpha protein triggers epithelial-mesenchymal transition and confers stem cell properties in normal human keratinocytes. J Biol Chem 286:38757-38767.

Phelps M, Darley M, Primrose JN and Blaydes JP (2003) p53-independent activation of the hdm2-P2 promoter through multiple transcription factor response elements results in ele- vated hdm2 expression in estrogen receptor alpha-positive breast cancer cells. Cancer Res 63, 2616-2623.

Plunkett J, Doniger S, Orabona G, Morgan T, Haataja R, Hallman M, Puttonen H, Menon R, Kuczynski E, Norwitz E, et al. (2011) An evolutionary genomic approach to identify genes involved in human birth timing. PLoS Genetics 7:e1001365.

Reich D, Green RE, Kircher M, Krause J, Patterson N, Durand EY, Viola B, Briggs AW, Stenzel U, Johnson PL, et al. (2010) Genetic history of an archaic hominin group from Denisova Cave in Siberia. Nature 468:1053-1060.

Ribeiro Junior CL, Arruda JT, Silva CT and Moura KK (2009) Analysis of $\mathrm{p} 53$ codon 72 gene polymorphism in Brazilian patients with endometriosis. Genet Mol Res 8:494-499.

Shan J, Brooks C, Kon N, Li M and Gu W (2008) Dissecting roles of ubiquitination in the p53 pathway. Ernst Schering Found Symp Proc 2008-1:127-136.

Shi H, Tan SJ, Zhong H, Hu W, Levine A, Xiao CJ, Peng Y, Qi $\mathrm{XB}$, Shou WH, Ma RL, et al. (2009) Winter temperature and $\mathrm{UV}$ are tightly linked to genetic changes in the p53 tumor suppressor pathway in eastern Asia. Am J Hum Genet 84:534-541.

Stewart CL, Kaspar P, Brunet LJ, Bhatt H, Gadi I, Kontgen F and Abbondanzo SJ (1992) Blastocyst implantation depends on maternal expression of leukaemia inhibitory factor. Nature 359:76-79.

Straub WE, Weber TA, Schafer B, Candi E, Durst F, Ou HD, Rajalingam K, Melino G and Dotsch V (2010) The C-terminus of p63 contains multiple regulatory elements with different functions. Cell Death Dis 1:e5.

Szklarczyk D, Franceschini A, Kuhn M, Simonovic M, Roth A, Minguez P, Doerks T, Stark M, Muller J, Bork P, et al. (2011) The STRING database in 2011: Functional interaction networks of proteins, globally integrated and scored. Nucleic Acids Res 39:D561-D568.

Tagliani-Ribeiro A, Oliveira M, Sassi AK, Rodrigues MR, Zagonel-Oliveira M, Steinman G, Matte U, Fagundes NJ and Schuler-Faccini L (2011) Twin Town in South Brazil: A Nazi's experiment or a genetic founder effect? PLoS One 6:e20328.

Tagliani-Ribeiro A, Paskulin DD, Oliveira M, Zagonel-Oliveira M, Longo D, Ramallo V, Ashton-Prolla P, Saraiva-Pereira ML, Fagundes NJ, Schuler-Faccini L, et al. (2012) High twinning rate in Cândido Godói: A new role for p53 in human fertility. Hum Reprod 27:2866-71.

Thomas M, Kalita A, Labrecque S, Pim D, Banks L and Matlashewski G (1999) Two polymorphic variants of wild-type p53 differ biochemically and biologically. Mol Cell Biol 19:1092-1100.

Toledo F, Krummel KA, Lee CJ, Liu CW, Rodewald LW, Tang M and Wahl GM (2006) A mouse p53 mutant lacking the proline-rich domain rescues Mdm4 deficiency and provides insight into the Mdm2-Mdm4-p53 regulatory network. Cancer Cell 9:273-285.

Tomasini R, Tsuchihara K, Wilhelm M, Fujitani M, Rufini A, Cheung CC, Khan F, Itie-Youten A, Wakeham A, Tsao MS, et al. (2008) TAp73 knockout shows genomic instability with infertility and tumor suppressor functions. Genes Dev 22:2677-2691.

Vousden KH and Prives C (2009) Blinded by the light: The growing complexity of p53. Cell 137:413-431. 


\section{Internet Resources}

Online Mendelian Inheritance in Man (OMIM). http://www.ncbi.nlm.nih.gov/OMIM (May 30, 2011).

International Agency for Research on Cancer (IARC) TP53 Mutation Database. http://www-p53.iarc.fr/index.html (May 30, 2011).

The International HapMap Project. http://hapmap.ncbi.nlm.nih.gov/ (May 30, 2011).

The ALlele FREquency Database (ALFRED). http://alfred.med.yale.edu/ (May 30, 2011).

Gene Ontology AmiGO browser. http://amigo.geneontology.org/cgi-bin/amigo/go.cgi (March 28, 2011).

STRING 9.0 software. http://string-db.org/ (March 28, 2011).

LALIGN software. http://www.ch.embnet.org/software/LALIGN_form.html (March 28, 2011).

GeneDecks V3 software. http://www.genecards.org/ (June 30/2011)

\section{Supplementary Material}

The following online material is available for this article:

- Table S1 - Frequencies of deleterious polymorphisms available in the HapMap database.

- Table S2 - Eighteen genes which influence the TP53 Fertility Network.

- Table S3 - Amino acid conservation of the Fertility Network genes.

- Table S4 - The variation and conservation of the Fertility Network genes.

- Table S5 - Non-coding variation and damaging prediction of Fertility Network genes.

This material is available as part of the online article from http://www.scielo.br/gmb.

License information: This is an open-access article distributed under the terms of the Creative Commons Attribution License, which permits unrestricted use, distribution, and reproduction in any medium, provided the original work is properly cited. 